\title{
Teratogenicity of monosodium glutamate on the pregnant rats and their fetuses
}

\author{
Abu Elnaga N.A. ${ }^{1}$, Sarhan M. ${ }^{2}$, Mansour H. ${ }^{1}$ \\ 1- Zoology Department, Faculty of Science, Al-Azhar University, Cairo (Girls branch) \\ 2- Zoology Department, Faculty of Science, Al-Azhar University, Assuit
}

\begin{abstract}
Background: $2 \%$ to $3 \%$ of all living newborns showed at least one recognizable congenital malformation. Monosodium glutamate (MSG) is widely used as flavor enhancer. But, it induces embryonic and fetal toxicity in rats during the gestational periods. Aim of the work: this study aimed to detect the effects of MSG on placenta and fetal developmental stages at $15^{\text {th }}$ and $19^{\text {th }}$ days of gestation. Material and Methods: fifty mature pregnant Albino rats (Weight $200 \pm 20 \mathrm{~g}$ ) were categorized into two groups according to the time of dissection at $15^{\text {th }}$ or $19^{\text {th }}$ days of gestation. From each group, half of the pregnant mothers (G15 and G19)were daily administrated MSG ( 7 $\mathrm{g} / 10 \mathrm{~mL} / \mathrm{kg} \mathrm{b}$. w. by oral)from the $9^{\text {th }}$ to $14^{\text {th }}$ days of gestation). The control groups (C15 and $\mathbf{C ~ 1 9 )}$ were received water only. Results: in G15 and G19 groups, the uterine and fetal shape, number of implantation sites, number of living fetuses, body length, fetal and placental weights and the placental co-efficient were negatively changed when compared to the control groups $(\mathbf{C 1 5}$ and $\mathbf{C}$ 19). Also, the placental tissue showed congested blood sinuses and large hemorrhagic areas which contained hemolysed blood cells. Some atrophied decidual cells and pyknotic nuclei were observed with highly distorted maternal and fetal placental layers. Conclusions: this study showed that shortterm MSG exposure caused several maternal and fetal changes. Therefore, MSG is considered as embryotoxic agent and the mothers must avoid administration of this substance during the gestation
\end{abstract} period.

\section{Introduction:}

The most critical period in embryonic development is when cell differentiation and morphogenesis are at their peak. At this time, the embryos are more susceptible to any teratogen ${ }^{(\mathbf{1})}$. Monosodium Glutamate (MSG) is one of the world's most extensively used food additives which are ingested as part of commercially processed foods. As a flavor enhancer, MSG increases the sapidity of food (2). A previous study showed that oral administration of MSG to pregnant rats influenced the body weight and hypothalamus of their offspring. Abnormalities of fetuses found in the limbs ranged from absence to various degrees of digits fusion on both anterior and posterior limbs ${ }^{(3)}$. The body and gravid uterine weights, number of implantations, growth rate of the viable offspring were affected after MSG treatment. MSG also induced some abnormal changes in gestation such as abortion and $\backslash$ or resorption of fetuses ${ }^{(4)}$. Miko et al. $^{(5)}$ and Hegazy et al. ${ }^{(6)}$ reported that monosodium glutamate exposure may cause severe intrauterine growth retardation, delayed maturation and degeneration of Wistar rats with histopathological changes in the fetal period. Monosodium glutamate (MSG) was shown to penetrate placental barrier and distribute almost evenly among embryonic tissues using $3 \mathrm{H}-\mathrm{Glu}$ as a tracer. When a lower $(1.0 \mathrm{mg} / \mathrm{g})$ and a higher $(2.5 \mathrm{mg} / \mathrm{g})$ doses of MSG were alternatively injected to Kunming maternal mice in every other days from mating to deliveries, obvious injury occurred in the ability of memory retention characteristic cytopathological changes induced by MSG showed swollen cytoplasm, dark pyknotic nuclei and loss of neurons. These experimental findings indicated that MSG performed its transplacental neurotoxicity in a dosedependent manner ${ }^{(7)}$.

\section{2 -Material and methods}

Animals: the present work was carried out on fifty mature pregnant Albino rats (Weight $200 \pm 20 \mathrm{~g}$ ). They were obtained from El -Rammed Medical Hospital, Cairo and 
housed in stainless steel cages (43 L X 30 WX $20 \mathrm{H} \mathrm{cm}^{3}$ ) and they were given free access standard chow and water ad libitum. The animals were kept in equal day-night cycle (12 $\mathrm{L}: 12 \mathrm{D})$ at room temperature $22 \pm 2{ }^{\circ} \mathrm{C}$ and stayed for 2 weeks for adaptation. The technical standards and international guidelines for research on animals were followed.

Mating: the female rats were completed at least two consecutive estrous cycles before use. Each two females in pro estrus or estrus periods were transferred to the cage of one fertile male. The presence of vaginal plug or sperms in the vaginal smear in the next morning was referred to success the mating. At this time, the zero day of pregnancy was recorded. The pregnant mothers were followed up by gradual increase in the body weight, a sudden decrease of their weight and /or presence of blood drops were considered as sings of abortion. The females who didn't mate during two estrus cycles were excluded from this study ${ }^{(8)}$.

Experimental design: fifty mature pregnant Albino rats (Weight $200 \pm 20 \mathrm{~g}$ ) were categorized into two groups according to the time of dissection (at $15^{\text {th }}$ or $19^{\text {th }}$ days of gestation). From each group, half of the pregnant mothers were considered as the control groups (C15 and C 19) and they were received water only. Another half from each group (G15 and G19) was administrated MSG $\left(7 \mathrm{~g} / 10 \mathrm{~mL} / \mathrm{kg}\right.$ b. wt. given orally ${ }^{(9)}$ (Sig. Che. Com.,USA). The treatment was given for 6 days during the $9^{\text {th }}$ to $14^{\text {th }}$ days of the gestational period.

\section{The morphological investigations:}

The pregnant mothers were dissected after anesthesia by Halothane (Pharco Comp). The uterine horns were removed from the surrounding fats and then freshly photographed. Then, the fetuses were removed from the surrounding amniotic membranes and cleaned before they weighted and photographed. The uterine shape, number of implantation sites, number of living and dead fetuses, the fetal weight $(\mathrm{g})$, the placental weight $(\mathrm{g})$, placental co-efficient $(\mathrm{g})$ \{ weight of placenta /weight of fetuses \}and the types of malformations were recorded.

\section{Histopathological and histochemical techniques:}

In the present study, some specimens of the placental tissue were fixed in $10 \%$ neutral buffer formol and the others in Carnoys' fluid for the histological and histochemical techniques. Then they were dehydrated in ascending grades of alcohol after washing, cleared in xylene and embedded in paraffin wax. The blocks of wax were cut $5 \mu$ in thickness and mounted on glass slides. For the histological and histopathologic examinations, some slides were stained with hematoxylin and eosin according to the method of Drury and Wallington ${ }^{(10)}$. After using Feulgen reaction ${ }^{(11)}$ in another slides, the optical density of DNA was recorded by image analysis by Bel Micro Program Analyzer Ver. 2.3 / 01.04, 2007 (www.belphotonics.com) .

-Statistical analysis: all data were presented as mean $\pm \mathrm{SD}$ values of $\mathrm{p}<0.05$ were considered statistically significant. The data were analyzed by using T test in SPSS 17.0 software (Excel program).

\section{Percent of change $=$}

Mean of treated - mean of control x 100 mean of control

-Laboratory facilities: the facilities including animal housing, histological and histochemical analysis were performed in Department of Zoology, Faculty of Science, Al-Azhar University (Girls branch).

This study followed the ethical guidelines of Faculty of Science, Al-Azhazr University.

\section{Results}

The implantation sites and uterine shape: the control pregnant rats which were dissected at the $15^{\text {th }}$ and $19^{\text {th }}$ days of gestation showed regular distribution of implantation sites and normal uterine shape and size. Also, the corpus luteum in the ovaries had been clearly observed. But, of course, the uterine size and their bugles were larger in $\mathbf{C 1 9}$ group than $\mathbf{C 1 5}$ group (Figs.1, 2). As shown in fig.3 and fig.4, the uteri were observed as very small bulges with empty spaces between them, atrophied ovary and early death of embryos were detected in the all the treated groups (G15 and G19). 

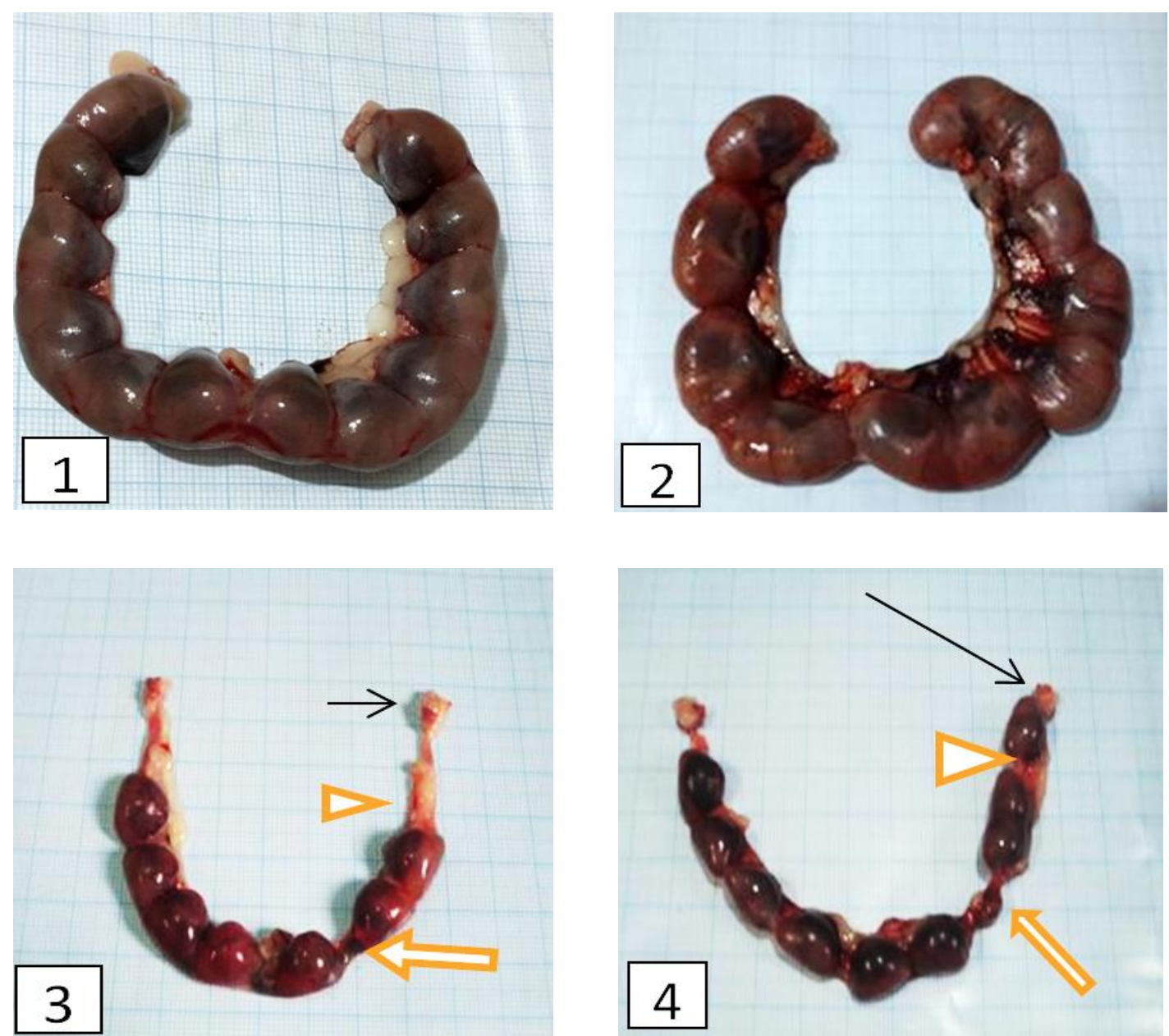

Figs.1-4: photographs of rat's wombs isolated at $15^{\text {th }}$ and $19^{\text {th }}$ days of gestation. Figs. 1, 2: showing normal distribution of implantation sites with normal size of uterine bulges of $\mathbf{C}_{\mathbf{1 5}}$ and $\mathbf{C}_{\mathbf{1 9}}$ respectively. Figs. $\mathbf{3}, \mathbf{4}$ : showing unequal distribution of implantation sites, very small bulges(live and late death fetuses), empty spaces in the uteri ( $\triangleright$ ), atrophied ovary $(\rightarrow)$ and early death of embryos as reabsorbed bodies $(\Longrightarrow)$ in both $\mathbf{G}_{\mathbf{1 5}}$ and $\mathbf{G}_{\mathbf{1 9}}$ groups.

\section{The placental co- efficient weight ( $g$ )}

Administration of MSG during organogenesis periods showed high significant decrease $(\mathrm{P} \leq 0.01)$ in the mean values of the fetal weight $(0.29 \pm 0.15 \mathrm{~g})$ in the mothers dissected at $15^{\text {th }}$ day of gestation to the control group C19 (3.58 $\pm 0.14 \mathrm{~g})$, the percent of change decreased to $-70.9 \%$ in $\mathbf{G 1 5}$ group and - $40.6 \%$ in G19 group (Table 1 , fig. 5). No significant change in the mean value of the placental weight was detected in G15 group $(0.23 \pm 0.10 \mathrm{~g})$ compared to the control group C15 $(0.28 \pm 0.05 \mathrm{~g})$ and the percent of change decreased to -17 . $79 \%$. Also, no significant change was recorded in group G19 $(0.37 \pm 0.14 \mathrm{~g})$ when compared to the control group $(0.40 \pm 0.11 \mathrm{~g})$ and the percent of change was decreased to $-7.5 \%$ in
(G15) compared to the control group (C15) $(0.99 \pm 0.20 \mathrm{~g})$. Also, there was a significant decrease $(\mathrm{P} \leq 0.05)$ in the mean values of the fetal weight in the mothers soaked MSG and dissected at $19^{\text {th }}$ of gestation ( Group G19) $\left(\begin{array}{llll}2.128 & \pm 0.41 & \mathrm{~g}\end{array}\right) \quad$ compared group G19 (Table 1 , fig. 6). Measurements of the placental co-efficient $(\mathrm{g})$ in the mothers of group G15 $(0.79 \pm 0.66 \mathrm{~g})$ showed a significant increase $(\mathrm{P} \leq 0.05)$ compared to the normal value $(0.28 \pm 0.10 \mathrm{~g})$ of $\mathbf{C 1 5}$ group. The mean value of $\mathbf{G 1 9}$ group reached $0.17 \pm$ $0.05 \mathrm{~g}$ compared to the normal value $0.11 \pm 0.02 \mathrm{~g}$, but increased percent of change was detected and reached $0.25 \%$ and $-0.18 \%$ in groups $\mathbf{G 1 5}, \mathbf{G 1 9}$ respectively compared to the normal control groups (Table 1 , fig. 7 ). 
Abu Elnaga N.A. et al.

Table 1: showing the statistical analysis of the mean values of the fetal and placental weights (g) and placental co- efficient (g) in the different experimental animals

\begin{tabular}{|c|c|c|c|c|}
\hline Groups & C15 & G15 & C19 & G19 \\
\hline Parameters & & & & \\
\hline Fetal weight (g) & 0.99 & $0.29 * *$ & 3.58 & $2.128^{*}$ \\
& \pm 0.20 & \pm 0.15 & \pm 0.14 & \pm 0.41 \\
\hline \% of change & & $-70.7 \%$ & & $40.6 \%$ \\
\hline Placental weight $(\mathbf{g})$ & 0.28 & 0.23 & 0.40 & 0.37 \\
& \pm 0.05 & \pm 0.10 & \pm 0.11 & \pm 0.14 \\
\hline \% of change & & $-17.79 \%$ & & $-7.5 \%$ \\
\hline Placental co-efficient $(\mathbf{g})$ & 0.28 & $0.79 * *$ & 0.11 & $0.17 *$ \\
& \pm 0.10 & \pm 0.66 & \pm 0.02 & \pm 0.05 \\
\hline \% of change & & $0.25 \%$ & & $-0.18 \%$ \\
\hline
\end{tabular}

-Each value represented the mean, \pm standard deviation (SD) and \% percent of change.

- The values are considered significant at $* \mathrm{P} \leq 0.05$ and highly significant at $* * \mathrm{P} \leq 0.01$ compared to the control group.

C15 and C19: control groups ; G15 and G19 administrated MSG and dissected at $15^{\text {th }}$ and $19^{\text {th }}$ days respectively.

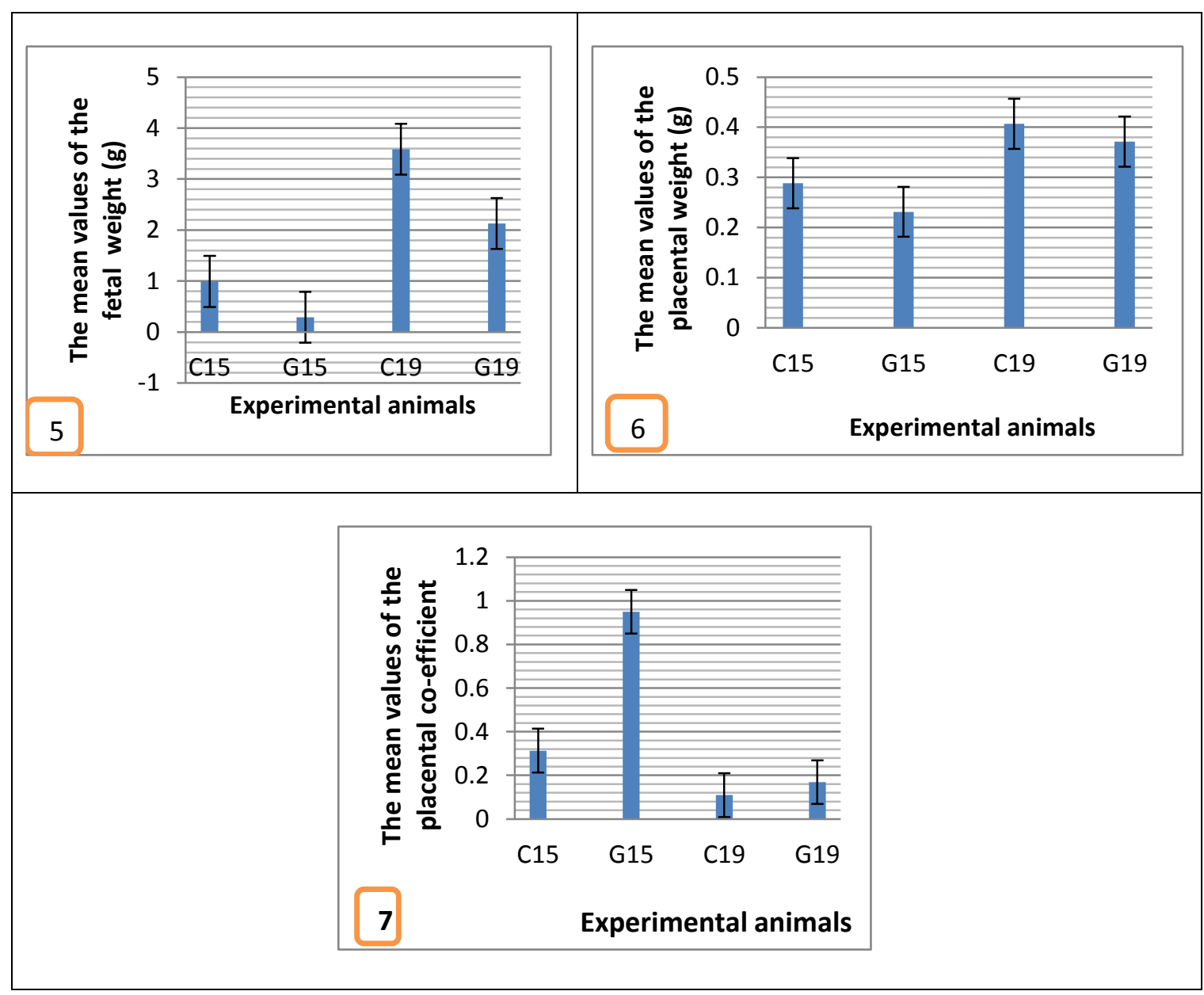

Figs. 5-7: histograms showing the mean values of the fetal and placental weight (g) and placental co- efficient (g) in the different experimental animals 
Fetuses malformations:-

As shown in Fig. 8b, the fetuses at $15^{\text {th }}$ day of gestation in the control group (C15) were morphologically normal. The characters of the head was appeared as facial clefts closed, pinna turns forward and covers more than half of the external auditory meatus, eyelids were opened, fore and hind limbs completely formed with toes separate and they are clearly divergent, the tail appeared clearly and transparent skin cover all the body. Fetuses of the treated mothers (G15) showed Small Gestational Age (SGA) (83\%), absence of ear pinna (83\%), atrophied eye $(67 \%)$ and edema in all the body $(50 \%)$, fore limbs were formed, but hind limbs were still buds $(100 \%)$ and the tail has not appear (83\%) (Table 2, figs. 8 a, 11 ). At $19^{\text {th }}$ day of

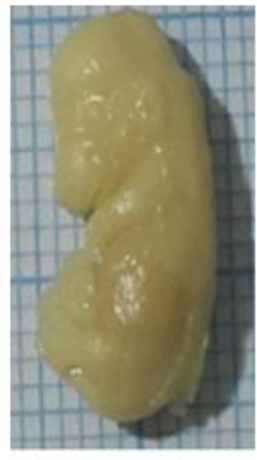

$8 a$

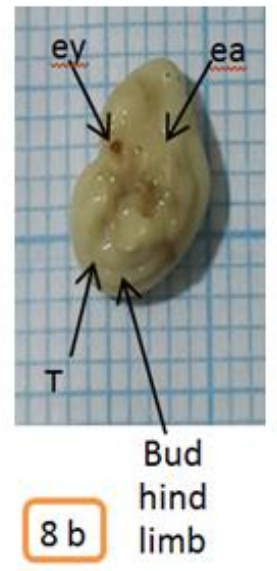

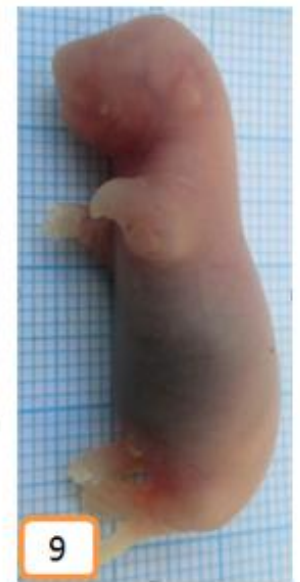

gestation, the control group (C19) had completely formed head, the whiskers were definitely longer with thickened skin, the pinna was large, the eyes were barely visible through the closed eyelids, palate complete, complete form of long bones fore and hind limbs, fingers and toes were parallel ,the umbilical hernia disappeared and tail length were $10 \mathrm{~mm}$ (Fig. 9 ). But in G19 group, MSG caused a decrease in the size of fetuses $(86 \%)$, very thin subcutaneous muscle layer (86\%), microcudate (short tails) ( $42.8 \%$ ), apalpebralia (absence of eyelids) (71.4\%), anotia (absence of ear pinna) (71.4\%) and some fetuses showed elongated and narrowed head $(71.4 \%)$, edema under the skin layer $(57.1 \%)$ and atrophied eye $(42.8 \%)$ (Table 2, figs.10a,10b,10c,11).
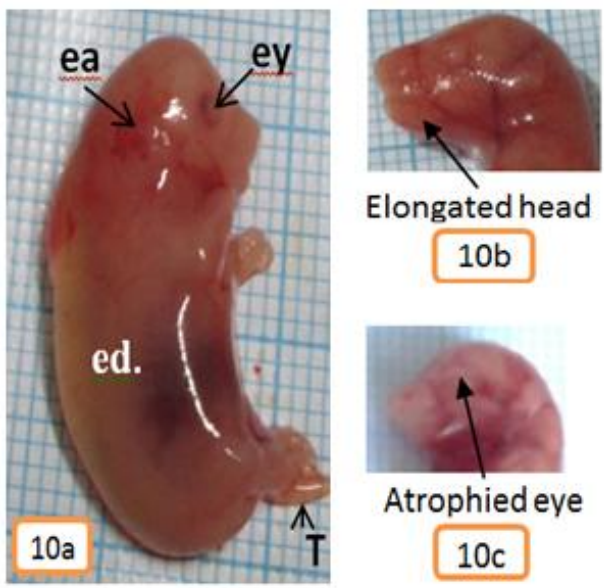

Fig. 8 (a,b): showing isolated fetuses at the $15^{\text {th }}$ day of gestation. Notice: normal morphological characters. head formation, facial clefts closed, pinna turns forward and covers more than half of the external auditory meatus, fore and hind limbs are completely formed with toes are separated, the tail appeared clearly and transparent skin covers all the body in the fetuses of the control group (C15, Fig. 8a ). Also, showing isolated fetus in $15^{\text {th }}$ day of gestation of group $\mathbf{G 1 5}$ (Fig. 8b ). Notice: growth retardation, absence of ear pinna (ea), atrophid eye (ey), hind limbs still bud and the tail does not appear (T). Figs. 9-10c : showing isolated fetuses at the $19^{\text {th }}$ day of gestation. Fig. 9: showing normal completely formed head, ear pinna, eyelids, palate, long bones of fore and hind limbs, the tail and the skin has thickened, fingers and toes become parallel and the umbilical hernia disappeared (C19 group ). Figs.10a-c: magnification of isolated fetuses in $19^{\text {th }}$ day of gestation of G19 group showing elongated head, very thin skin, thin skin and subcutaneous muscle layer, micro caudate (T), apalpebralia (ey), anotia (ea) and edema (ed) .

Table 2: showing the percentage of fetal malformations in G15 and G19 groups with compared to the normal control group

\begin{tabular}{|l|c|c|}
\hline malformations & Groups & G19 \\
\hline Small Gestational Age (SGA) & $83.3 \%$ & $86 \%$ \\
\hline Atrophied eye & $67 \%$ & $42.80 \%$ \\
\hline Thin skin and weakly muscle & $83 \%$ & $86 \%$ \\
\hline bud hind limbs & $100 \%$ & $0 \%$ \\
\hline Micro caudate & $83 \%$ & $42.80 \%$ \\
\hline Edema & $50 \%$ & $57.10 \%$ \\
\hline Anotia & $83 \%$ & $71.40 \%$ \\
\hline
\end{tabular}




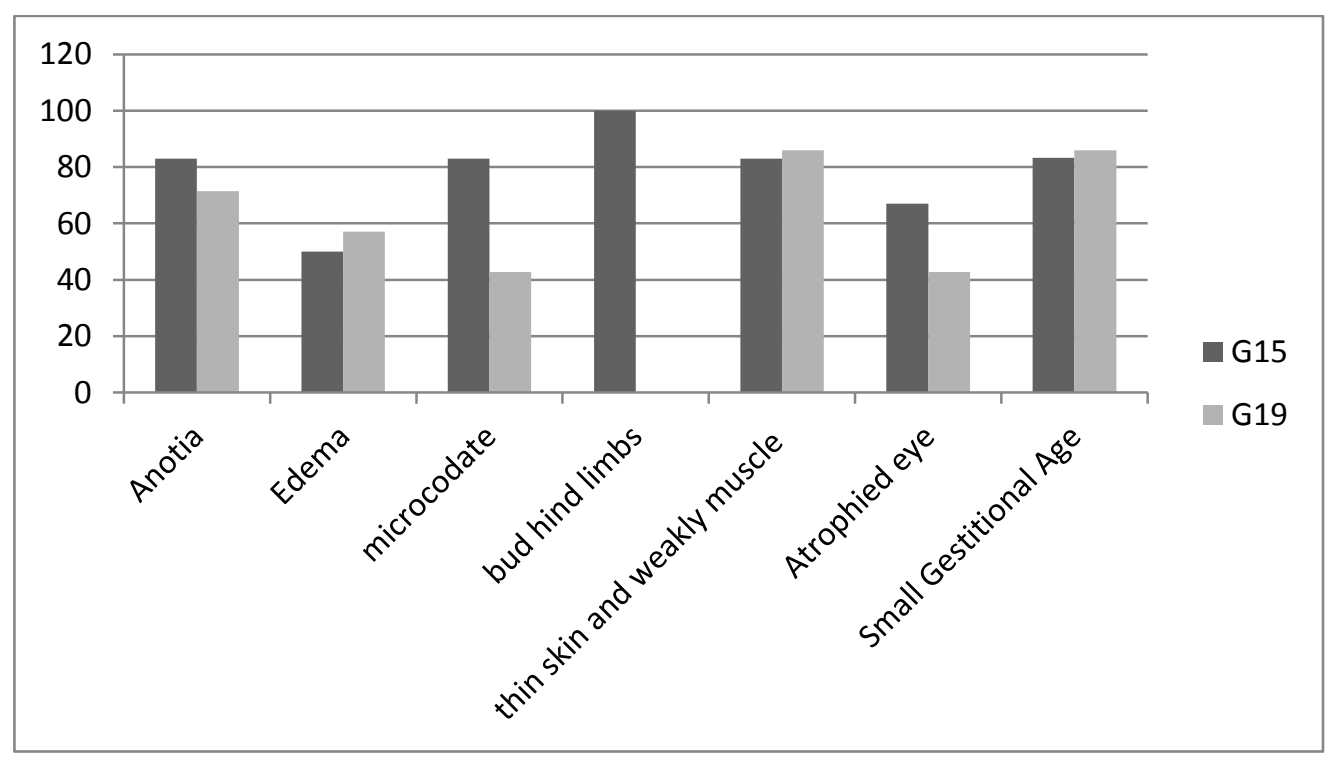

Fig.11: histogram showing percentage of fetal malformations in G15 and G19 groups with compared to the normal control group
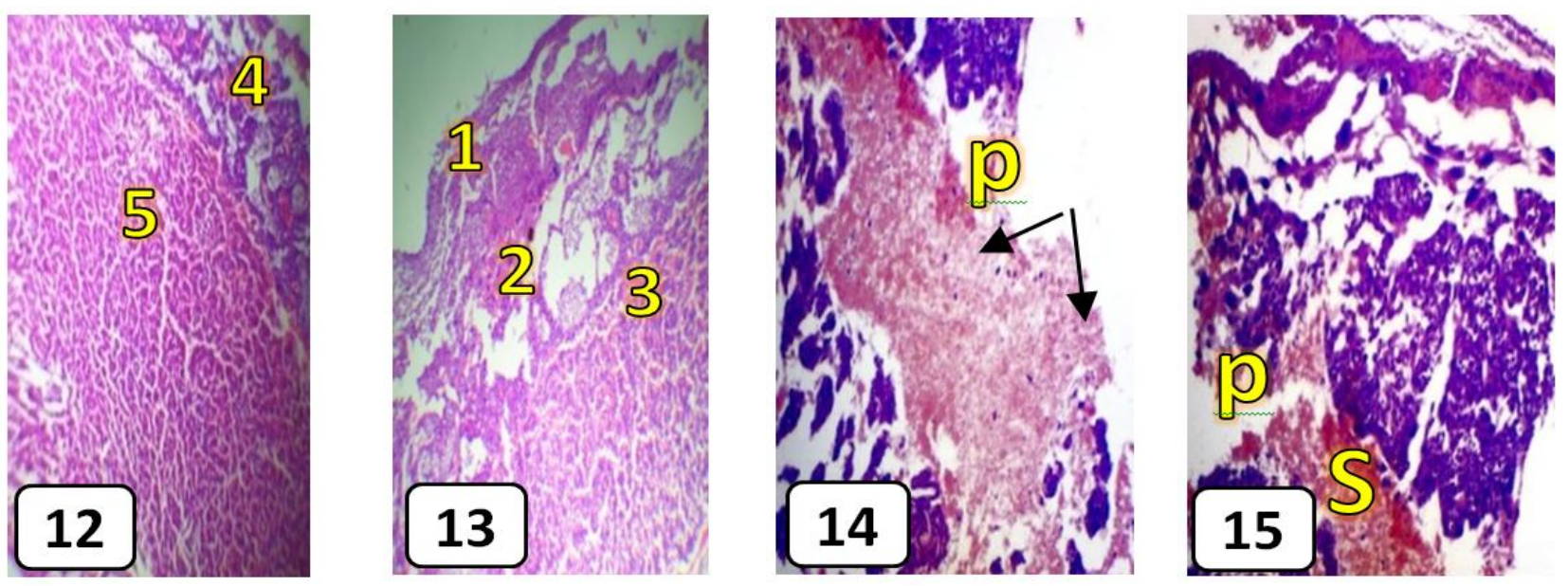

Figs. 12-15 :showing photomicrographs of placenta of the control $\mathbf{C 1 5}$ and treated G15 groups stained with hematoxyline and eosin. Figs. 12, 13: showing normal placental tissue of the control group C15) fibrinoid coat, 2) sinuses of maternal blood, 3) decidual cells, 4) basal lamina , 5) fetal placenta with lots of fetal blood sinuses (H\&EX 100).

Figs. 14, 15: showing placental tissue of a rat of group G15with congested maternal and fetal blood sinuses (s) and large hemorrhagic areas which contain hemolysed blood cells $(\uparrow)$,atrophied decidual cells with pyknotic nuclei (p) (H\&E X 200).

\section{Placenta tissue:-}

Normal placental tissue of the control groups $(\mathbf{C 1 5}, \mathbf{C 1 9})$ showed the arrangement of different layers of the placenta which started with fibrinoid coat then sinuses of maternal blood layer followed by decidual cells, basal lamina and finally fetal placenta with lots of fetal blood sinuses (Figs. 12,13, 16, 17). Placental tissue of a rat of group G15 showed many congested maternal and fetal blood sinuses and large hemorrhagic areas which contained hemolysed blood cells, atrophied decidual cells with pyknotic nuclei, highly distorted maternal and fetal tissues with large hemorrhagic areas beside the fetal placenta (Figs. 14, 15 ). Placenta tissue of rats of group G19 showed numerous degenerative changes in the maternal and fetal placentae. These changes included : highly dilated and congested maternal and fetal blood sinuses which contained hemolysed blood cells, completely vacoulated cytoplasm of the decidual cells with pyknotic nuclei, degenerated and necrotic areas in the maternal placenta and degenerated areas in the fetal placenta with highly distorted chorionic villi (Figs. 18, 19) . 


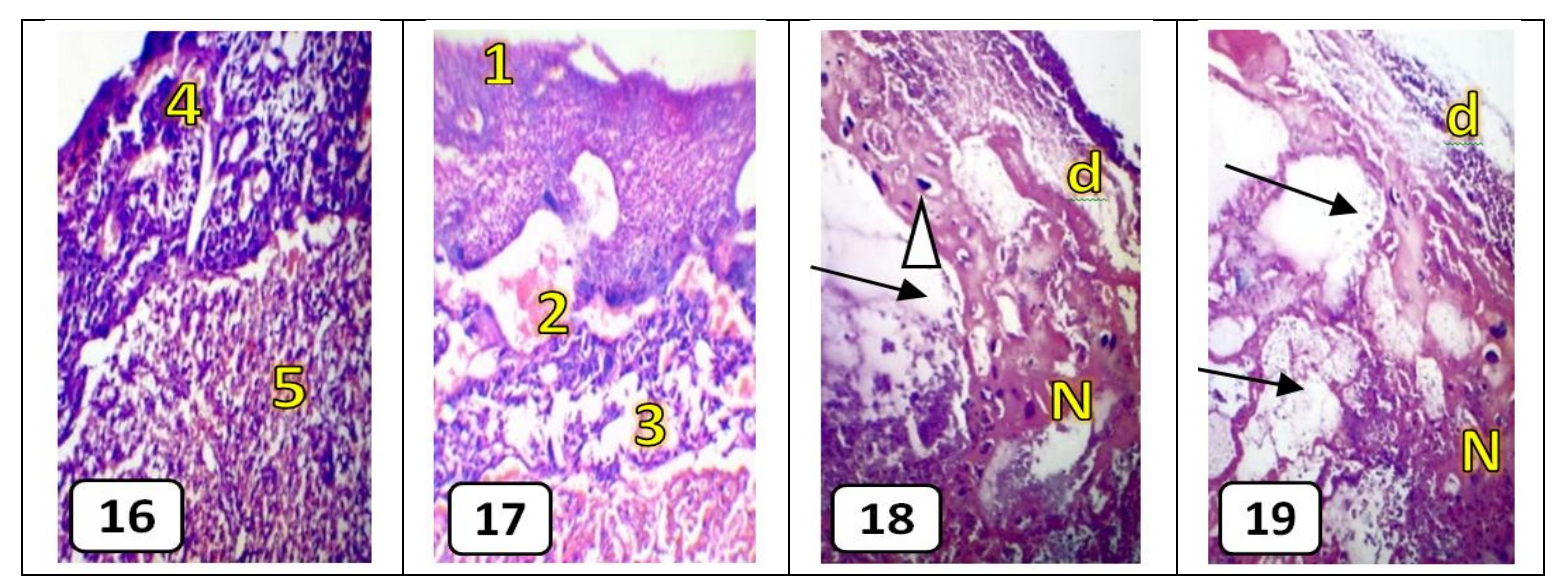

Figs. 16- 19: showing photomicrographs of placenta of the control and treated groups on day 19 of gestation stained with hematoxyline and eosin. Figs. 16, 17: showing placental tissue of rats of the control group C19. Notice: 1) fibrinoid coat, 2) sinuses of maternal blood, 3) decidual cells, 4) basal lamina 5) fetal placenta with lots of fetal blood sinuses .Figs. 18, 19: showing placenta tissue of rats of group G19. Notice: numerous degenerative changes in the maternal and fetal placentae. These changes include: highly dilated and congested maternal and fetal blood sinuses $(\uparrow)$ which contain hemolysed blood cells, completely vacoulated cytoplasm of the decidual cells with pyknotic nuclei $(\Delta)$,degenerated $(\mathrm{d})$ and necrotic $(\mathrm{N})$ areas in the maternal placenta and degenerated areas (d) in the fetal placenta (H\&EX 200).

\section{The histochemical studies of the placental tissue:-}

Table 3 and figure 20 showed measurement of the mean optical density values (MOD) of DNA materials in the placenta tissue of animals sacrificed on day $15^{\text {th }}$ of gestation in the different experimental groups. The mean value of DNA materials in the placenta tissue of the control group C15 showed moderately to densely stained DNA materials in the placental tissue of the control group especially in nuclei of decidual basalis cells .The optical density recorded160.47 \pm 69.46 MOD in the maternal layer and $140.04 \pm 63.21 \mathrm{MOD}$ in the fetal layer of the placenta of the $\mathbf{C 1 5}$ group . While, DNA materials value of group $\mathbf{G 1 5}$ showed decreased staining affinity of DNA materials in the maternal and fetal placental tissue and reached $59.18 \pm 27.44$ MOD in the maternal layer of the placenta of $\mathbf{G 1 5}$ group .DNA materials in the fetal layer of the placenta and reached $57.56 \pm 29.02$ MOD. Percentage of change of DNA materials reached about $-63.12 \%$ in the maternal layer of placenta and reached to $-58.89 \%$ in the fetal layer of placenta of group G15.Table 3 and figure 21 showed measurement of the mean optical density values (MOD) of DNA materials in the placenta tissue of animals scarified on day $19^{\text {th }}$ of gestation in the different experimental groups. The mean value of DNA materials in the placenta tissue of the control group C19showed moderately to densely stained DNA materials in the placental tissue of the control group .DNA materials recorded $172.66 \pm 74.48 \mathrm{MOD}$ in the maternal layer and $174.59 \pm 75.46 \mathrm{MOD}$ in the fetal layer of the placenta of $\mathbf{C 1 9}$ group. While, DNA materials value of group G19 showed decreased staining affinity of DNA materials in the maternal and fetal placental tissue and recorded 48.62 \pm 25.32 MOD in the maternal layer of the placenta of $\mathbf{G 1 9}$ group. DNA materials reached $42.81 \pm 21.66$ MOD in the fetal layer of placenta of G19 group. The percentage of change of DNA materials reached$71.84 \%$ in the maternal layer of placenta and reached $-75.47 \%$ in the fetal layer of placenta in group G19.

Table 3: showing the optical density values (MOD) of DNA materials in the placenta at $15^{\text {th }}$ and $19^{\text {th }}$ days of gestation of all groups

\begin{tabular}{|c|c|c|c|c|}
\hline \multirow{2}{*}{ Parameters } & \multicolumn{2}{|c|}{ Fetuses } & \multicolumn{2}{c|}{ Mothers } \\
\cline { 2 - 5 } & C & G & C & G \\
\hline \multirow{2}{*}{ G15 } & 140.04 & $57.56^{* *}$ & 160.47 & $59.18^{* *}$ \\
& \pm 63.21 & \pm 29.02 & \pm 69.46 & \pm 27.44 \\
\hline \% of change & & $-58.89 \%$ & & $-63.12 \%$ \\
\hline \multirow{2}{*}{ G19 } & 174.59 & $42.81^{* *}$ & 172.66 & $48.62^{* *}$ \\
& \pm 75.46 & \pm 21.66 & 74.48 & \pm 25.32 \\
\hline
\end{tabular}




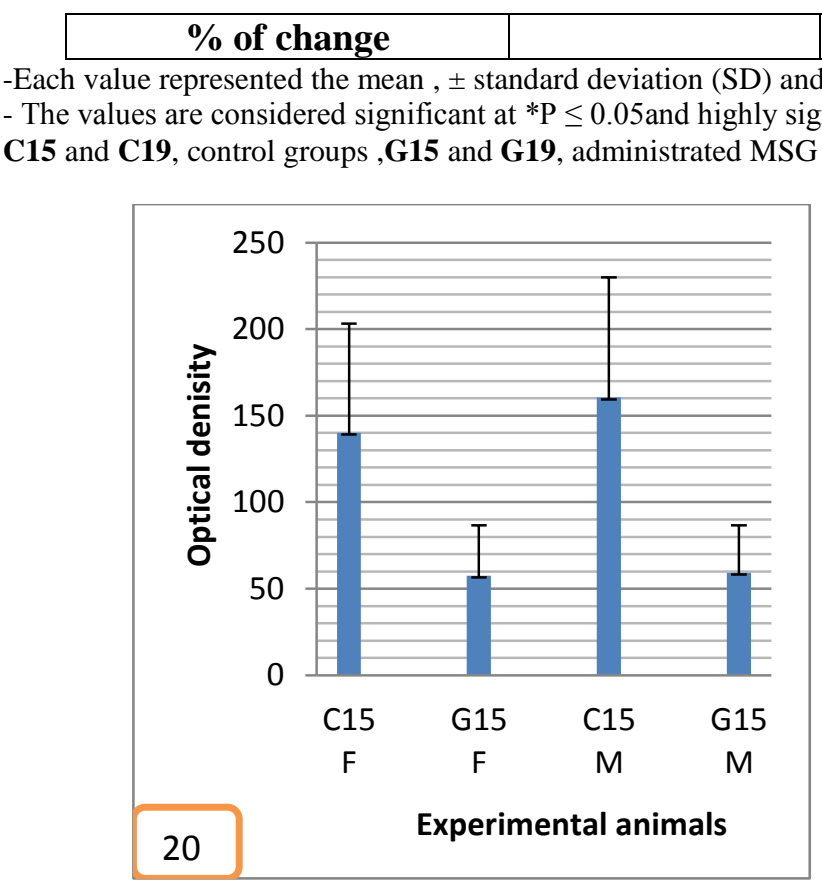

$$
-75.47 \%
$$

-Each value represented the mean, \pm standard deviation (SD) and percent of change (\%).

- The values are considered significant at $* \mathrm{P} \leq 0.05$ and highly significant at $* * \mathrm{P} \leq 0.01$ compared to the control group.

$\mathbf{C 1 5}$ and C19, control groups, G15 and G19, administrated MSG and dissected in $15^{\text {th }}$ and $19^{\text {th }}$ days respectively.

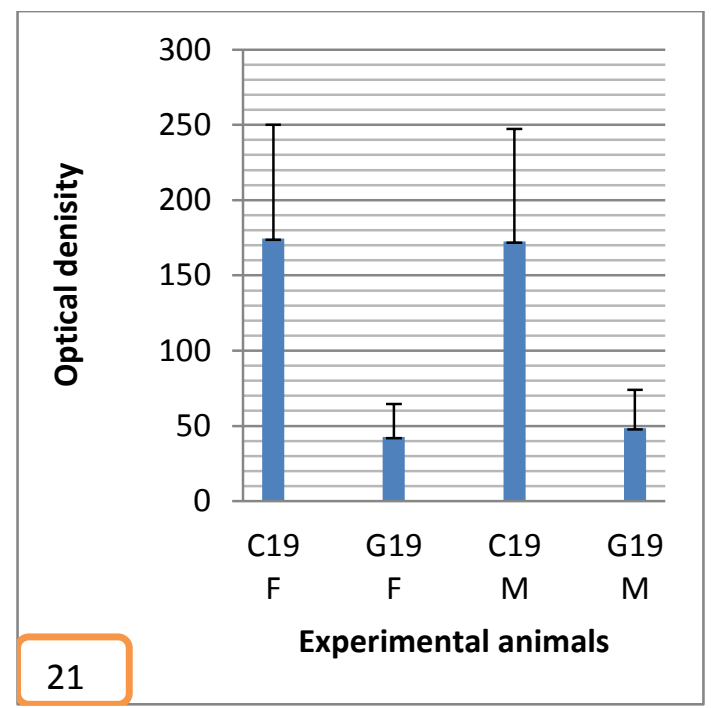

Figs.20, 21: histograms showing the mean optical density values (MOD) of DNA materials in the placenta at $15^{\text {th }}$ and $19^{\text {th }}$ day of gestation of all groups

\section{Discussion}

Many bad eating habits of pregnant mothers can harm the health of their fetuses. In the present study, the toxic effect of Chinese salt (MSG) on the pregnant rats was observed at $15^{\text {th }}$ and $19^{\text {th }}$ days of gestation. The uteri shape showed small bulges with empty spaces between them, unequal distribution of implantation sites, atrophied ovary and some malformed embryos. The number of implantation sites showed no significant change in the mothers daily treated with MSG and this may be due to the time of treatment (from $9^{\text {th }}$ to $14^{\text {th }}$ days of gestation)that exceeded the implantation period. Roy George et al. ${ }^{(4)}$ observed that low dose of MSG $(0.4 \mathrm{~g} / \mathrm{kg}$ body weight) reduced the number of rat embryos and some resorbed bodies were seen. The number of implantation sites did not show any significant change in oral administration of MSG during and after the implantation period (from $0-15^{\text {th }}$ days of gestation) when compared to the control group. Also, some abnormal changes $(25 \%)$ in gestation such as abortion or absorption of fetuses were seen. The early death of embryos may be due to anemic condition of mothers after oral injection of MSG. Ibrahim et al. ${ }^{(12)}$ found that the hemoglobin and red blood cells count were all indicative of an anemic condition in the MSG treated mice. On another hand, the incidence of abortion may be happened after reduction of progesterone hormone due to atrophic action of MSG on the ovary. Oladipo et al. ${ }^{(13)}$ found that MSG $(0.20 \mathrm{~g} / \mathrm{kg})$ for 14 days caused degenerative and atrophic changes in the ovaries of Sprague-
Dawley rats and these changes were more severe at the higher doses.

The present study showed that administration of MSG during organogenesis period decreased the mean values of the fetal weight in the mothers at $15^{\text {th }}$ or $19^{\text {th }}$ days of gestation compared to the control value. The percent of decrease was $-70.7 \%$ in G15 group and improved after stopping the treatment (at day 14 of gestation) to $-40.6 \%$ in G19 group. Husarova and Ostatnikova ${ }^{(14)}$ reported that administration of MSG $(4.0 \mathrm{mg} / \mathrm{kg})$ deceased the pituitary gland growth hormone level which is responsible of fetal growth. Also, Ibrahim et al. ${ }^{(12)}$ reported that administration of MSG decreased the count of RBC's and $\mathrm{Hb}$ values resulting in blood anemia which undermined the living fetuses and reduced their weights. Nandan et $\boldsymbol{a l} .{ }^{(\mathbf{1 5})}$ reported that MSG inhibited the leptin signaling and plays a critical role in regulation of body weight. In another possibility, non controlled leptin reaction may lead to insulin resistance that is a fundamental aspect linked to a wide array of diseases including hypertension, hyperlipidemia and atherosclerosis. Administration of MSG induced hypothalamic neurotoxicity accompanied by metabolic disorders, including obesity, a transient insulin resistance and metabolic alterations in the blood lipotoxicity in the liver and skeletal muscle. These metabolic disorders were responsible for decrease in the fetal weight by the decrease in Activated Protein Kinase (APK) phosphorylation which acts on the insulin receptor substrate and activates the insulin signaling. The present study showed that the placental weight was decreased in the treated mothers when compared to the normal groups (C15 
and C19). The percentage of decrease was $-17.79 \%$ in G15 group and improved to $-7.5 \%$ in $\mathbf{G 1 9}$ group. Ciobanu et al. (16) explained the impact of hypertensive disorders to induce the deficiency in platelets (Thrombocytopenia). The thrombotic microangiopathy is characterized by endothelial injury, followed by platelet aggregation and thrombus formation in small vessels. So, this means that the coagulated blood reaches the placenta and accumulates inside the placental barriers and then decreased the amount of blood that reach to the fetuses. The placental coefficient correlates the weight of a fetus and the placenta. In normal condition the placental weight increased according to the birth weight. The placental weight to birth weight ratio decreased slightly with advancing gestational age. A previous study showed that under the teratogenic factors, the placental coefficient was disturbed (17). The present study confirmed the previous researches, after oral administration of MSG for six days, the percent of change in the placental co-efficient weight $(\mathrm{g})$ was $0.25 \%$ and $-0.18 \%$ in $\mathbf{G 1 5}$ and $\mathbf{G 1 9}$ groups respectively compared to the normal values. Begum et al. ${ }^{(18)}$ stated that maternal anemia had frequently been interpreted as evidence of compensatory hypertrophy for reduced oxygen supply. It is possible in the way that fetal hypoxaemia develops due to lower hemoglobin concentration in the placental circulation, usually stimulates placental growth. As shown in a previous study, MSG has some harmful effects such as oxidative stress, DNA damage, protein modification and lysis of stromal cells ${ }^{(19)}$. The present work showed $83 \%$ and $71.4 \%$ palpebralia in G15 and G19 groups respectively. This is in agreement with a previous study which confirmed that MSG might block the central eye artery and lead to monophathalmia or anophthalmia (20). Another study investigate the effects of high dietary intake of MSG on the rat and rabbit eyes ${ }^{(21)}$. They found that MSG caused extensive retinal damage and marked electroretinogram attenuation (a record of the electrical activity of the retina). Immature animals were found to be much more vulnerable to the toxic effects of MSG than older animals especially in the inner layers of eyes. The results of the present study showed Small Gestational Age (SGA) in the fetuses of $\mathbf{G 1 5} \operatorname{group}(83.3 \%)$ and in the G19 group $(86 \%)$ compared to the normal control group. This may be explained by the findings of Hermanussen et al. ${ }^{(2)}$ who establish that severe reduction $(\mathrm{P} \leq 0.01)$ in birth weight and growth hormone serum levels in rats after receiving MSG (5 g MSG per day)were detected during the prenatal life. Infants with intrauterine growth restriction (IUGR) were distinct from those who were small of gestational age (SGA), although the terms have been used interchangeably. Conditions cause IUGR result in impaired placental function, which effectively renders the fetus malnourished and chronically hypoxic. In the present work, IUGR was observed in the fetuses of MSG treated mothers compared to the control group. The percentage of malformations in G15 group was $83 \%$ anotia and $83 \%$ microcaudate. The fore limbs were not formed, but the hind limbs were still buds. After finishing the treatment period (at $14^{\text {th }}$ day of gestation), the fetuses were improved in G19 group and the percentage of malformations was decreased to $42.8 \%$ micro caudate, $71.4 \%$ anotia but, some fetuses showed elongated and narrowed head. Intrauterine growth restriction (IUGR) is often seen in association with pregnancies complicated by pregnancy- induced hypertension (PIH) or the HELLP syndrome, chronic hypertension and maternal diabetes mellitus ${ }^{(23)}$.The results of the current study are explained also by a previous research which studied the genotoxic effects of $\mathrm{MSG}^{(24)}$. They investigated the potential genotoxicity of dietary MSG mediated by oxidative damage in intraperitonially treated rats at dose $4 \mathrm{mg} / \mathrm{g}$ body weight. Shredah ${ }^{(25)}$ proved marked reduction in DNA quality and quantity in the palatal mucosa of rats by MSG and the reduction in DNA quantity was dose depended in comparison with the control group. Fetal maceration was observed in the present study with very thin skin $(83 \%)$ and subcutaneous edema (50\%) in G15 group. This percentage was increased to $86 \%$ very thin skin and $57.1 \%$ edema in $\mathbf{G 1 9}$ group. Fetal maceration takes place upon intrauterine fetal death (IUFD) and is a process characterized by enzymatic autolysis of cells and degeneration of connective tissue leading to skin discoloration, desquamation with formation of bullae and eventually skin peeling, as well as edema of the outer and inner organs with turbid effusions inside the fetal body and amniotic cavity (26). Muin et al. ${ }^{(27)}$ proved that the higher grades of fetal deterioration, as denominator for prolonged fetal retention caused hematological changes in the maternal system with increased risk of disseminated intravascular coagulation (DIC) in this population after intrauterine fetal death(IUFD). A coagulopathy was associated with a preexisting preeclampsia / hemolysis, elevated liver enzymes, low platelet (HELLP) syndrome as a result of intrauterine fetal death (IUFD). Also, Ajibola et al. (28) suggested that administration of MSG for 14 days at different doses caused thrombocytopenia (a decrease in platelet cell count). They also stated that thrombopoietin hormone is secreted by the kidneys and produces platelet cells and the high doses of MSG decreased the secretion of this hormone by renal failure. In the present study, placental tissue of rats of group G15 showed many congested maternal and fetal blood sinuses and large hemorrhagic areas beside the fetal placenta which contained hemolyzed blood cells, atrophied 
decidual cells with pyknotic nuclei, highly distorted maternal and fetal tissues. Placental tissue of rats of group G19 showed numerous degenerative changes in the maternal and fetal placentae. These changes included highly dilated and congested maternal and fetal blood sinuses which contained hemolyzed blood cells, completely vacoulated cytoplasm of the decidual cells with pyknotic nuclei, degenerated and necrotic areas in the maternal placenta and degenerated areas in the fetal placenta with highly distorted chorionic villi. Kizer et al. ${ }^{(29)}$ stated that treatment of rat's neonates with monosodium glutamate resulted in regenerative lesions in the hypothalamus. The neurotoxic effect of MSG in the hypothalamus was restricted to arcute nucleus (AN) and it had been described in neonatal chickens, hamsters, guinea pigs, rats and mice. All cell types within the AN appeared to be affected and exhibited intracellular edema. Subsequent to dendritic necrosis, neurophagia occurred with macrophage infiltration. Their histological examination indicated that the neurotoxic effects on glial cells, ependymal cells and axons of passage were reversible with permanent damage. All this damage affected placental tissue and caused degenerated and necrotic areas in the maternal and fetal placentae. Mosaad and Sabry ${ }^{(30)}$ reported that daily oral administration of high dose $(8 \mathrm{~g} / \mathrm{kg}$ b.wt. MSG) for long duration (3 months) on young male and female Albino rats significantly increased serum tumor necrosis factor $-\alpha(\mathrm{TNF}-\alpha)$ and interlukin-1 $\beta$ (IL1- $\beta$ ) levels in the treated groups. MSG killed body cells and caused neuro endocrine

\section{References:-}

1. Carlson B M (2009): Human Embryology and Developmental Biology. $4^{\text {th }}$ ed. Mosby El Sevier, Philadelphia. P. 312.

2. Mondal T , Bag I, Sngvl P, Garikapati K, Bhadra U and Bhadra M (2018): Two way controls of apoptotic regulators consign .doi.org/10.1371/journal.pone.0190548.

3. Olney $\mathbf{J} \mathbf{W}$ and Sharpe $\mathbf{L} \mathbf{G}$ (2003): Brain lesions in an infant rhesus monkey treated with monosodium glutamate. Science, $166: 401-421$.

4. Roy George K, Shibija N G and Malini N A (2013): Monosodium glutamate (MSG) induced developmental dysfunction in female albino rats (Rattus norvegicus). An International Journal of Life Sciences, 8(1): 73-76.

5. Miko AM, Shehu AM, Bello N, Allyu I A, Tasiu I, Abdussalam AO and Isa A S ( 2016): A morphometric study of the teratogenic effect of monosodium glutamate on the developing developing cerebral cortex of Wista Rat(Rattus norvegicus). Nigerian Journal of Scientific Research, 15(3): 240-244.

6. Hegazy A A, Ibrahim I H, Sabry R M and Abass E S (2017): Effect of gestational exposure to monosodium glutamate on the structure of fetal rat lung. Anatomy Physiol. Biochem. Int. J., 3(2):1-6. disorders in the experimental animals and that it caused adverse reaction in human. Free glutamic acid combined with sodium and it is a neurotransmitter that caused nerves die. MSG acted as exitotoxin (31). Ciobanu et al. (16) found endothelial injury followed by platelet aggregation and thrombus formation in small vessels which caused coagulated blood associated with blood pressures then reach to placenta and aggregation in the placental barriers and damage it.Also, there was intravascular coagulation (DIC) after intrauterine fetal death (IUFD) ${ }^{(27)}$. Results of the present study showed that DNA materials in the placenta tissue of the control group C15 were moderately to densely stained especially in nuclei of decidual basalis cells. The percentage of change of DNA materials was decreased to $-58.89 \%$ in the fetal layer of placenta and reduced to $-63.12 \%$ in the maternal layer of placenta in group G15. The percentage of change of DNA materials was decreased to $-75.47 \%$ in the fetal layer of placenta and reduced to $-71.84 \%$ in the maternal layer of placenta in group G19. These findings were explained by Shredah ${ }^{(25)}$ and Calis et al. ${ }^{(32)}$ who found that MSG had increased oxidative stress and inflammation in the different organ systems. It also caused glucose metabolism disorders, obesity and coronary diseases which caused defect in blood circulation of all organs. Kumbhare et al. ${ }^{(33)}$ and Hamdy et al. ${ }^{(34)}$ found that there were nuclear pyknosis in all tissues treated with MSG and this may be due to DNA damage .

7. Gao J, Wu J, Zhao XN, Zhang W N, Zhang Y Y and ZhangZ X (1994): Transplacental neurotoxic effects of monosodium glutamateon structures and functions of specific brain areas of filial mice. Sheng Li. Xue. Bao., 46(1): 44-51.

8. Abd Rabu M (2013): Modulation of radiation injury in pregnant rats by bone marrow transplantation. M.Sc. Zoology Department, Faculty of Science, Al-Azhar University, Cairo.

9. Nayanatara A K , Vinodini N A , Ahemed B , Ramaswamy C R , Shabarianth $G$ and Ramesh M (2008): Role of ascorbic acid in monosodium glutamate mediated effect on testicular weight, sperm morphology and sperm count in rat testis. Journal of Chinese Clinical Medicine, 3:1-5.

10. Drury $\mathbf{R}$ and Wallington E (1967): Carlton's Histological Technique. 4th ed., Oxford. Univ. Press, New York, p.432.

11. Drury R and Wallington E (1980): Carleton's Histological Technique, 4th Ed. Oxford. Univ. Press, New York, Toronto.

12. Ibrahim O M S , Abdul hamza $\mathrm{N} \mathrm{N}$ and Abbass $\mathrm{H}$ K (2012): Some hematological and histological impact of sub-acute exposure to monosodium glutamate in mice. Proceeding of the Eleventh Veterinary Scientific Conference, 20(12) : 127131. 
13. Oladipo I C, Adebayo E A and Kuye O M (2015): Effects of monosodium glutamate in ovaries of female Sprague-Dawley rats. Int. J. Curr. Microbiol. App. Sci ., 4(5): 737-745.

14. Husarova V and Ostatnikova D (2013): Monosodium glutamate toxic effects and their implications for human intake: a review. doi: 10.5171/2013.608765.

15. Nandan P, Nayanatara A K, Poojary R, Bhagyalakshmi $K$, Nirupama $M$ and Kini $R$ D (2018): Protective role of co-administration of vitamin $\mathrm{D}$ in monosodium glutamate induced obesity in female rats .J. National Medic. Assoc., 110(1): 98-102.

16. Ciobanu A M , Colibaba S , Cimpoca B , Peltecu G and Panaitescu A (2016) : Thrombocytopenia in pregnancy. Maedica (Buchar), 11(1): 55-60.

17. Mansour H (2014): Experimental studies on pregnant diabetic rats treated with olive leaves. M. Sc. Zoology Department, Faculty of Science, AlAzhar University, Cairo.

18. Begum M, Ara S, Kishwara S, Nurunnabi A S and Rayhan K A (2010):Microscopic changes of the placental componentsin maternal anemia. Bangl. J. Anat., 8: 59-63.

19. Mustafa Z, Ashraf S, Tauheed S F and Ali S (2017): Monosodium glutamate commercial production positive and negative effects on human body and remedies - a review. I. J. S.R.S.T., 3: 425-435.

20. Tamas A, Gabriel R, Racz B, Denes V, Kiss P, Lubics A, Lengvari I and Reglodi D (2009): Effect of pituitary adenylatecyclase activating polypeptide in retinal degeneration induced by monosodium- glutamate. Neuroscience lett., 372(1-2):110-113.

21. Ali M M, Bawari M, Misra U K and Babu G N (2012): Locomotor and learning deficits in adult rats exposed to monosodium-L-glutamate during early life. Neuroscience Letters, 284(1-2): 57-60.

22. Hermanussen M, Garcia A P, Sunder M, Voigt M, Salazar V and Tresguerres J A (2006): Obesity voracity and short stature: the impact of glutamate on the regulation of appetite. Eur. J. Clin. Nutr., 60(1):25-31.

23. Duley L, Meher S and Abalos E (2006): Management of pre-eclampsia. Br. Med . J., 332:463-468.

24. Farombi E O and Onyema OO (2006): Monosodium glutamate induced oxidative damage and genotoxicity in rat: modulatory role Vitamin C, Vitamin E and quercetin. Hum. Exp. Toxicol., 25(5): 251-259.
25. Shredah M T (2017): Molecular study to the effect of monosodium glutamate on rat gingiva. Tanta Dental J., 14(3): 155-163.

26. Khong T Y et al. (2016): Sampling and definitions of placental lesions. Amsterdam Placental Workshop Group Consensus Statement. Archives of Pathology and Laboratory Medicine, 140:698713.

27. Muin D, Haslacher H, Koller V, Kiss $1 \mathrm{H}$, Scharrer A and Farr A (2018): Impact of fetal maceration grade on risk of maternal disseminated intravascular coagulation after intrauterine fetal death . A retrospective cohort study. doi:10.1038/s41598-018-30687-0.

28. Ajibola M, Oloruntoba A C, Chinomso U A and Shekins O (2012): The Effects of orally administered monosodium glutamate (MSG) on blood thrombocyte, blood coagulation and bleeding in rats. Journal of Pharmacy and Biological Sciences, 4(1): 4-8.

29. Kizer J, Nemeroff C and Young W(1997): Blood neuretoxic amino acids and structurally related analogs . Pharmacol. Rev., 29: 301-318.

30. Mosaad R M and Sabry HA (2017):Toxicity of monosodium glutamate on articular cartilage in young male and female albino rats: oxidative stress, pro-inflmmmatory cytokines and free amino acids. International Journal of Medical Research and Pharmaceutical Sciences, 4(2):3340.

31. Waer H F and Edress S (2006): The effect of monosodium glutamate (MSG) on rat liver and the ameliorating effect of "guanidino ethane sulfonic acid (GES)" (Histological, histochemical and electron microscopy studies). The Egyptian Journal of Hospital Medicine, 24: 524 - 538.

32. Calis I U, Cosan D T et al. (2016): The effects of monosodium glutamate and tannic acid on adult rats. Iran Red. Crescent Med. J., 18(10):1-7.

33. Kumbhare V, Gajbe U, Singh B R, Reddy A K and Shukla S (2015): Histological and histochmical changes in liver of adult rats treated with monosodiume glutamate: a light microscopic study. World Journal of Phamacy and Pharmaceutical Sciences, 4 (4): 898-911.

34. Hamdy GM , Saleh E M and Seoudi D M (2018): Does monosodium glutamate induce genotoxic stress through altering gadd $45 \mathrm{~b}$ gene expression? Research Journal of Pharmaceutical Biological and Chemical Sciences, 9(3):1058-1070. 